\title{
Younger physicians providing less direct patient care
}

Family physicians who were under the age of 45 in 2003 provided, on average, 8.8 fewer hours of direct patient care each week than physicians of the same age group in 1982. According to the CMA Physician Resource Questionnaire (PRQ) results, this represents a $21 \%$ decrease.

The 45-54 age group provided 3.8 fewer hours by 2003 . In contrast, those 55-64 and 65 and over spent 0.4 and 4.7 more hours respectively per week on direct patient care in 2003 than they did 2 decades earlier. (See CMA7 2002;166[11]:1407-11.)

The difference between age groups in hours worked has shrunk in recent years. In 1982, the gap between the age group working the longest hours $(<45)$ and those working the least $(65+)$ was 14 hours per week. The difference now

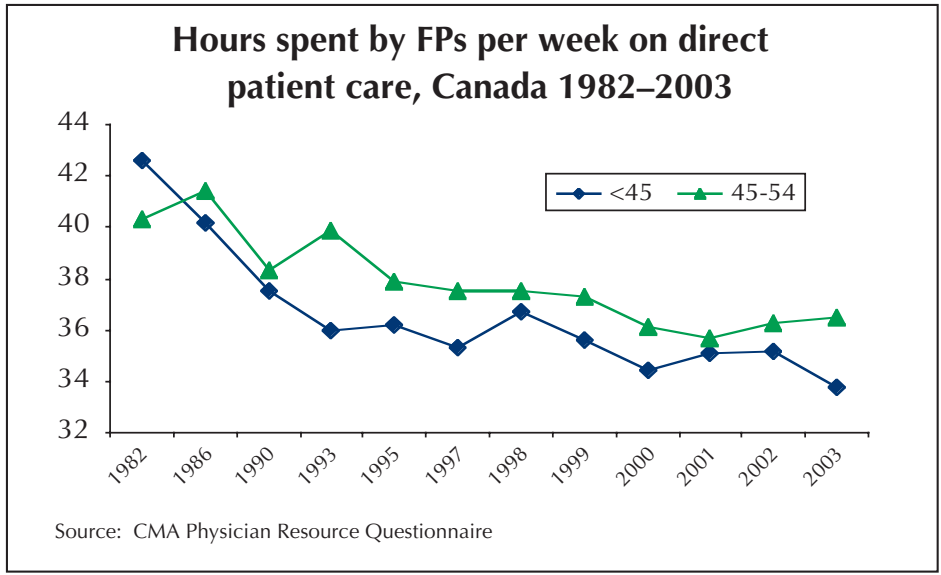

is only 4.7 hours per week.

It should be noted that direct patient care alone does not reflect the total workload of physicians, which includes on-call responsibilities, other patient-related activities such as completing forms, charting and phone calls, and committee work, research, teach- ing and administration.

The PRQ was mailed to a random sample of 7922 doctors, and the response rate was $28.4 \%$. National results are accurate to within $\pm 2.1 \%$, Buske, Associate Director of Research, CMA 19 times out of 20.-Lynda

\section{INTERNATIONAL Health}

\section{Regulation of natural health products challenged}

Opponents to state regulation of natural health products won a major victory when the London High Court gave a coalition of industry and consumer groups the go-ahead to appeal a European Union (EU) directive restricting food and vitamin supplements.

The challenge was granted in February and is expected to be heard later this year at the European Court of Justice, which has the sole power to overturn an EU directive.

The London judge ruled there is an "arguable case," for the appeal. The coalition says the regulations are unlawful, threaten health and trade and undermine consumer choice.

The directive, which is now slated to come into effect in August 2005, will produce a list of approved products and restrict the upper limits of supplement doses. Its architects say it will harmonize the natural health prod- ucts market, promote free movement of goods and ensure consumer protection. Critics worry that such a list will result in the retraction of thousands of vitamins and supplements including calcium, zinc and selenium.

Beate Gminder, spokesperson for the Health and Consumer Protection branch of the European Commission, said "It is not our intention to ban products nor to increase costs. But we feel very clearly that the industry producing food supplements needs to have some data to support [product] safety."

The Alliance for Natural Health, an organization of supplement manufacturers, retailers, practitioners and consumers that filed one of the challenges in the High Court, declared the ruling "a victory for millions of consumers of advanced food supplements, many of whom have found good health using nutrition as a central approach."

The ruling comes as international organizations and governments on 3 continents are reevaluating or implementing legislation of complementary medicines. Canada's new federal regulations came into effect Jan. 1 (CMA7 2004;170(6):940), and new US legislation is expected to quash the 1994 Dietary Supplements Health and Education Act. Last year Australia created a new drugs agency that will classify and regulate dietary supplements and alternative remedies as pharmaceuticals.

The World Health Organization has entered the fray, issuing guidelines to ensure the quality and sustainability of the production of herbal medicines, an area that their report says is "difficult to regulate properly and get safety assurance for patients." - Jocalyn Clark, London 